\title{
Immunization Rates and Barriers to Influenza Vaccine Access in the Community Pharmacy
}

\section{Kyle Melin ${ }^{1^{\star}}$}

111160 Lost Creek Terrace \#105, Lakewood Ranch, FI 34211, USA

*Corresponding author: Kyle Melin, 11160 Lost Creek Terrace \#105, Lakewood Ranch, FI 34211, USA, Tel: 787-402-3727; E-mail: nr376@nova.edu

Received date: May 05, 2017; Accepted date: May 11, 2017; Published date: May 15, 2017

Copyright: (C2017 Rodríguez NM, et al. This is an open-access article distributed under the terms of the Creative Commons Attribution License, which permits unrestricted use, distribution, and reproduction in any medium, provided the original author and source are credited.

\section{Background}

The Advisory Committee on Immunization Practices (ACIP) recommends the annual influenza vaccine for everyone 6 months of age and older [1]. Annual flu vaccination is the most effective way to prevent influenza and its complications. In the past, the most common setting to get the vaccine among adults has been doctor's offices. However, the percentage of people vaccinated against influenza in a non-medical setting was higher for whites (44\%) compared to Hispanics (34\%) [2]. Non-medical places of influenza vaccination include pharmacies, stores, workplace and schools [3]. Pharmacists' role as immunization providers is growing. The Center for Disease Control and Prevention (CDC) estimates that pharmacists administered approximately $22 \%$ of the 2010-11 influenza adult vaccinations [4]. Currently, pharmacists are providing immunization against influenza in all fifty states, Washington DC, and Puerto Rico [5]. In 2010, law 7 amended the Puerto Rico Pharmacy Practice Act to authorize pharmacists to immunize people eighteen years old and over against several diseases, including influenza, by protocol. This law is intended to promote preventive health services and to facilitate access to vaccines. Law 7 supports the Healthy People 2020 objectives that include increasing the percentage of adults who are vaccinated annually against seasonal influenza [6,7].

In Puerto Rico, 1.6 million people are covered by the government health plan. Government health insurance provides coverage for influenza vaccine with no copayment. However, 3 many pharmacies can and do charge the patient a five-dollar vaccine administration fee. During the 2012-13 influenza season, only 160,000 (10\%) of the government health insurance population was vaccinated. During the 2013-14 influenza season the Department of Health of Puerto Rico's goal was to vaccinate 200,000 people $(12.5 \%$ of the government health insurance population) against influenza before December 2013 [8]. Several studies have previously described the factors that influence the patient decision to become vaccinated against seasonal influenza. Shavell et al. identified some patient barriers to influenza vaccination during pregnancy in the United States including: safety concerns, lack of knowledge about influenza, fear of needles, vaccination history, and access to care [9]. Börjesson \& Enander (2013) examined demographic factors and perceptions among the general public in Sweden related to the decision to become vaccinated against A/H1N1 influenza. Some factors of importance for the decision regarding vaccination were: to prevent spreading the disease, worry about becoming ill oneself, and concerns about side effects. Additionally, demographic factors including sex, age group, annual income and educational level were correlated with vaccination rates [10]. Johnson et al. found that some common reasons that consumers in the United States reported for not getting the influenza vaccine included: not receiving specific instruction to do so from the physician and the perception that a healthy person does not need vaccination against influenza [11].

The primary objective of this study is to determine the influenza immunization rates of the government health insurance population in a community pharmacy in Lares, Puerto Rico. A 4 secondary objective is to assess the factors that influence the access to the influenza vaccine in Puerto Rico.

\section{Methods}

\section{Study setting}

The prospective, survey-based study was conducted in a community pharmacy in Lares, Puerto Rico during the period March to May of 2014. Data was collected by administering a short questionnaire to study participants about the 2013-14 flu season vaccination.

\section{Study participants}

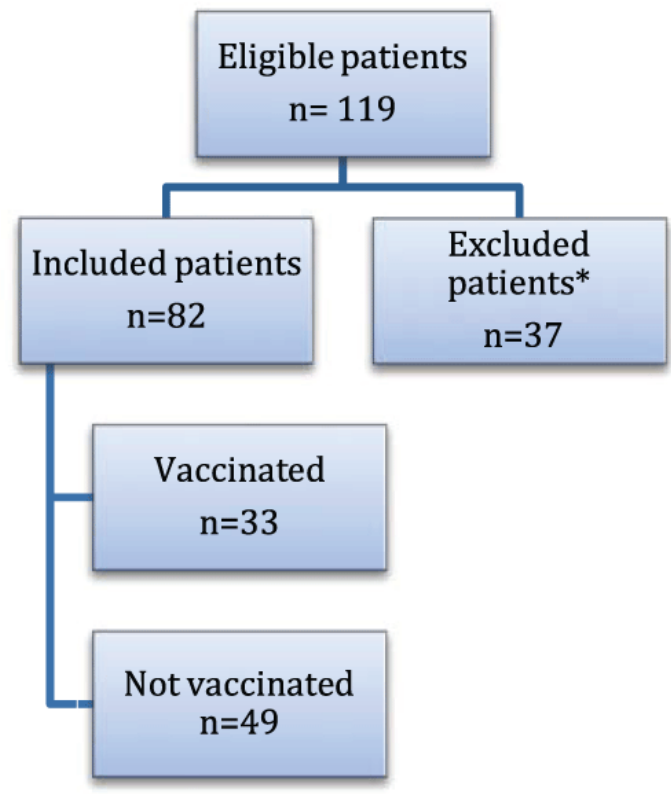

*Excluded patients were not beneficiaries of the government health insurance Mi Salud.

Eligible patients were invited orally to participate in the study when they visited the pharmacy to deliver prescriptions, pick up 
medications, and receive pharmaceutical services. A study Informational Sheet approved by the Institutional Review Board was provided to the potential study participants. Inclusion criteria were: patients who are beneficiaries of the health insurance Mi Salud and those 21 years of age or older (21 is the age of majority in Puerto Rico). The following subjects were excluded: patients unable to answer a brief, written questionnaire due to developmental or psychological limitations, people with life expectancy of less than six months, and people with any type of dementia.

\section{Questionnaire}

The questionnaire consisted of seven questions and required approximately 3 minutes to complete. Each questionnaire has an ID number in a sequential order. The questions were written in Spanish, which is the primary language of this patient population. The first four questions collected socio-demographic information of the patient. Personal variables such as gender, age, monthly income, and education level were recorded. Following demographic questions, the questionnaire assessed whether or not the participant was vaccinated during the previous (2012-13) influenza season. Then, participants answered whether or not the patient was vaccinated during the current (2013-14) influenza season and, if so, if the individual was vaccinated at a community pharmacy. If the participant indicated they have not been vaccinated, the reason for not being vaccinated was assessed. The questionnaire contained a list of potential reasons to choose from. The participant also had the alternative "other", where they could add their own reasons for not getting vaccinated that were not listed on the questionnaire (Figure 1).

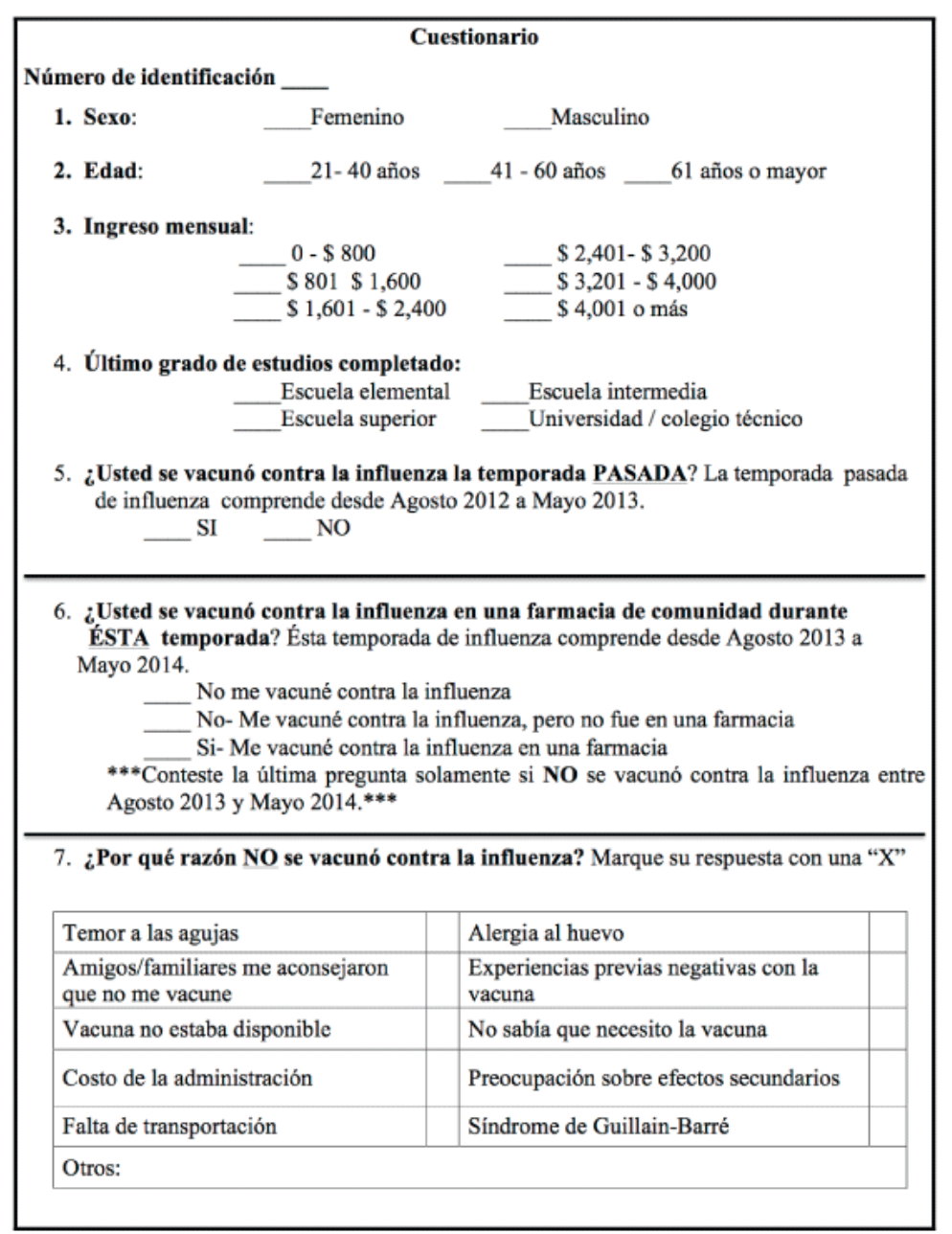

Figure 1: Questionnaire.

\section{Data Analysis}

Descriptive analysis and Cochran-Mantel-Haenszel method were used to examine frequencies and relative risk. Dichotomous variables were classified as those who received the flu shot, and those who did not get vaccinated. Also, associations between socio demographic variables and the reasons for not getting vaccinated were evaluated. All statistical analyses were performed using Statistical Analysis Software (SAS). 


\section{Results}

\section{Demographics variables}

Most study participants were women (57.32\%), aged 21 to 40 years (42.68\%), with a low monthly income $(71.95 \%)$ and had completed either secondary or post-secondary education (70.37\%). Table 1 summarizes the results of the demographic characteristics of patients by gender, age, monthly income and educational level.

\begin{tabular}{|c|c|c|}
\hline Variable & Frequency & Percent (\%) \\
\hline \multicolumn{3}{|l|}{ Gender } \\
\hline Female & 47 & 57.32 \\
\hline Male & 35 & 42.68 \\
\hline \multicolumn{3}{|l|}{ Age (years) } \\
\hline $21-40$ & 35 & 42.68 \\
\hline $41-60$ & 29 & 35.37 \\
\hline$\geq 61$ & 18 & 21.95 \\
\hline \multicolumn{3}{|c|}{ Monthly Income (Dollars) } \\
\hline $0-800$ & 59 & 71.95 \\
\hline $801-1,600$ & 18 & 21.95 \\
\hline $1,601-2,400$ & 2 & 2.44 \\
\hline $2,401-3,200$ & 2 & 2.44 \\
\hline $3,201-4,000$ & 0 & 0 \\
\hline 4,001 or over & 1 & 1.22 \\
\hline \multicolumn{3}{|l|}{ Education level } \\
\hline Elementary School & 14 & 17.28 \\
\hline Middle School & 10 & 12.35 \\
\hline High School & 27 & 33.33 \\
\hline College/University & 30 & 37.04 \\
\hline
\end{tabular}

Table 1: Demographics Characteristics.

\section{Influenza immunization rates}

Of a total 82 patients who completed the questionnaire, 49 patients (59.76\%) were not vaccinated against influenza during the current flu season (2013-14), 16 patients (19.51\%) were vaccinated but not at a pharmacy and 17 patients (20.73\%) were vaccinated in a community pharmacy. The absolute percentage of Mi Salud beneficiaries vaccinated against 7 influenza during the 2013-14 seasons was $40.24 \%$. The question about the influenza vaccination history for the past season (2012-13) revealed that even more patients were not vaccinated against influenza during the previous 2012-13 season [57 patients (69.51\%)] when compared to the current 2013-14 season.

\section{Reasons for not getting vaccinated against influenza}

Participants were asked about the reasons for not getting vaccinated against influenza during the current 2013-14 season. Potential responses included: fear of needles, lack of transportation, vaccine not available, administration fee, friend/family advice not to receive, allergy to egg, previous negative experiences with vaccination, did not know I needed it, concerns about side effects, Guillian-Barre Syndrome, and other. The top three reasons for not getting vaccinated against influenza were: other (26\%), concerns about side effects (24\%) and fear of needles (17\%). In the section "other" participants clarified: "I have seen many negative things about vaccines on television", "My brother told me that vaccines are harmful", "I am not interested in vaccination", "I did not know that I have to get a flu shot every year", "I was sick", "negligence", "lack of time", and "I have a scar on my arm because the doctor administered the vaccine incorrectly". Table 2 describes the reasons why patients decided not to get vaccinated against influenza by frequency and percent.

\begin{tabular}{|l|l|l|}
\hline Reasons & Frequency & $\begin{array}{l}\text { Percent } \\
(\%)\end{array}$ \\
\hline Fear of needles & 11 & 17 \\
\hline Lack of transportation & 4 & 6 \\
\hline Vaccine not available & 6 & 9 \\
\hline Administration fee & 2 & 3 \\
\hline Friends/family advice not to receive & 2 & 3 \\
\hline Allergy to egg & 0 & 0 \\
\hline Previous negative experiences with vaccination & 2 & 3 \\
\hline Did not know I needed it & 6 & 9 \\
\hline Concerns about side effects & 16 & 24 \\
\hline Guillain-Barre Syndrome & 0 & 0 \\
\hline Other & 17 & 26 \\
\hline
\end{tabular}

Table 2: Reasons for not get vaccinated against influenza.

The associations between demographic variables and the vaccination against influenza were analyzed. The past flu season vaccination history variable showed a statistically significant increase of relative risk ( $p$-value $<0.0001$ ) for not being vaccinated in the 8 current flu season. Table 3 summarizes the association between age, gender and flu vaccination history with the decision to get vaccinated against influenza.

\begin{tabular}{|c|c|c|}
\hline Variable & Relative Risk & $\begin{array}{l}95 \% \quad \text { Confidence } \\
\text { Interval }\end{array}$ \\
\hline Gender & 1.2083 & $0.4957-2.9457$ \\
\hline Age & 1.248 & $0.4338-3.5901$ \\
\hline $\begin{array}{l}\text { Past flu season vaccination } \\
\text { history }^{\star}\end{array}$ & 9.7262 & $3.2432-29.1680$ \\
\hline \multicolumn{3}{|c|}{ "p-value $<0.0001$ (SSD=statistically significant difference) } \\
\hline
\end{tabular}

Table 3: Associations between demographic variables and vaccination against influenza. 


\section{Discussion}

The influenza immunization rate in the study participants is significantly higher than government rates reported for the previous year (40.24\% vs. $10 \%)$. However, this finding may be associated with sampling bias because the questionnaire was administered in a community pharmacy. Those patients that visit the pharmacy were more likely to be exposed to advertisements and pharmacist counselling about the influenza vaccine than those who might not regularly visit the pharmacy. The patients' most frequently reason for not getting vaccinated was "other". The patient's answers were mainly related to the information that they received about the vaccine in the media or through their family members. On other hand, some people demonstrated an overall lack of information regarding the flu vaccine. Therefore, pharmacist can play an important role in raising immunization rates in this patient population through appropriate patient education and better accessibility to the influenza vaccine.

\section{Conclusion}

Influenza is a preventable virus that can cause serious complications in people with certain health conditions, elderly and children increasing the risk of hospitalizations and death. To increase immunization rates and to overcome access barriers to influenza vaccine, we must consider partnering with other health professionals using collaborative agreements. 9 In this way the population can receive the right information about the influenza vaccine from reliable sources. Future studies should consider the relationship between immunization rates and government expenditures on hospitalizations and complications related to the influenza virus.

\section{Disclosure}

Authors of this article have nothing to disclose concerning possible financial or personal relationships with commercial entities that may have a direct or indirect interest in the subject matter of this research.

\section{References}

1. Grohskopf LA, Shay DK, Shimabukuro TT, Sokolow LZ, Keitel WA, et al. (2013) Prevention and control of seasonal influenza with vaccines: Recommendations of the advisory committee on Immunization practices- United States.

2. Singleton JA (2011) Influenza vaccination distribution and coverage, United States, 2010-11 and 2011-12 Seasons.

3. Kennedy ED, Santibanez TA, Bridges CB, Singleton JA (2012) Flu vaccination coverage, National Flu Survey, March 2012. Retrieved October, 2 2013, from Centers for Disease Control and Prevention.

4. Rothholz MC (2011) Pharmacists as partners in adult vaccinations, APhA.

5. Terrie YC (2010) Vaccinations: The expanding role of pharmacists. Pharmacy Times.

6. Pharmacists authorized to immunize Act of 2010

7. Healthy People 2020 Topics and objectives (2010) Immunization and infectious diseases.

8. Brote de influenza en municipios del Este. (2013) El Oriental Newsletter, Ed. 1810.

9. Shavell VI, Moniz MH, Gonik B, Beigi RH (2012) Influenza immunization in pregnancy: overcoming patient and health care provider barriers. Am J Obstet Gynecol 3: S67-74.

10. Börjesson M, Enander A (2013) Perceptions and sociodemographic factors influencing vaccination uptake and precautionary behaviors in response to the A/H1N1 influenza in Sweden. Scand J Public Health.

11. Johnson DR, Kristin NL, Lipczynski K (2008) Barriers to adult immunization. Am J Med 121: S28-S35. 